\title{
CORRIGENDUM ALTERNATIVE MONETARY POLICIES UNDER KEYNESIAN ANIMAL SPIRITS
}

\section{TAI-KuANG Ho}

National Taiwan University

\section{YA-CHI LIN}

Feng Chia University

KuO-Chun YeH

National Taiwan University

DOI: $10.1017 /$ S136510051800072X

In the above article, the affiliations for Tai-Kuang Ho and Ya-Chi Lin have been listed incorrectly as National Tsing Hua University and Hubei University of Economics, respectively.

However, the correct affiliations are National Taiwan University and Feng Chia University, respectively. Also, e-mail address are added for the authors Tai-kuang Ho (taikuangho@ntu.edu.tw) and Ya-chi Lin (yaclin@fcu.edu.tw). 